\title{
Operationalizing Legitimacy*
}

\author{
Eric W. Schoon \\ The Ohio State University
}

PLEASE CITE:

Schoon, Eric W. 2022. “Operationalizing Legitimacy.” American Sociological Review 87(3):478-503. doi:10.1177/00031224221081379

\footnotetext{
* I want to thank Gary Adler, Colin Beck, Jonah Stuart Brundage, Mathieu Desan, Douglas Downey, Şahan Savaş Karataşl1, Thomas Maher, David Melamed, Simeon Newman, Vincent Roscigno, Lesley Schneider, Robin Stryker, Xiaohong Xu, and Kara Young. This work benefited tremendously from their thoughtful and constructive feedback. I am especially grateful for multiple rounds of discussion with David Melamed. I want to thank Ronald Breiger, Joseph Galaskiewicz, Charles Ragin, and Robin Stryker for the many conversations and lessons that shaped my understanding of legitimacy. I also want to thank Christopher Kleps for his excellent research assistance. Previous versions of this article benefited from the feedback of participants at the Ohio State Department of Sociology Power, Inequality, and Economy (SocPIE) workshop, and the Penn State Department of Sociology Culture and Politics workshop. I am grateful to the ASR editors and three anonymous reviewers for their helpful advice, questions, and constructive encouragement. Finally, I want to thank Danielle van Dobben Schoon who has provided invaluable feedback and unending encouragement through every stage of this project. Please direct correspondence to Eric W. Schoon (schoon.1@osu.edu).
} 


\begin{abstract}
:
Legitimacy is widely invoked as a condition, cause, and outcome of other social phenomena, yet measuring legitimacy is a persistent challenge. In this article, I synthesize existing approaches to conceptualizing legitimacy across the social sciences to identify widely agreed upon definitional properties. I then build on these points of consensus to develop a generalizable approach to operationalization. Legitimacy implies specific relationships among three empirical elements: an object of legitimacy, an audience that confers legitimacy, and a relationship between the two. Together, these empirical elements constitute a dyad (i.e., a single unit consisting of two nodes and a tie). I identify three necessary conditions for legitimacy-expectations, assent, and conformity - that specify how elements of the dyad interact. I detail how these conditions can be used to empirically establish legitimacy (and illegitimacy), distinguishing it from dissimilar phenomena that often appear similar empirically. Followed to its logical conclusion, this operationalization has novel implications for understanding the effects of legitimacy. I discuss these implications, and how they inform debates over the relevance of legitimacy as an explanation for socially significant outcomes.
\end{abstract}


In contemporary social scientific research, legitimacy is an indeterminate conceptwidely used, but empirically nebulous. Legitimacy is central to research on institutions (DiMaggio and Powell 1983), law (Stryker 1994), mobilization (Walker and McCarthy 2010), politics (Beetham [1991] 2013), crime (Bradford, Jackson, and Hough 2013), stratification (Jost and Major 2001), and many other phenomena. Over the past century, multidisciplinary scholarship has advanced important insights into both the causes and effects of legitimacy (Jackson 2018; Johnson, Dowd, and Ridgeway 2006; Risse and Stollenwerk 2018; Suchman 1995), and much of this work traces its intellectual heritage to a common set of foundational texts (i.e., Weber [1921] 1978, 2004).

Yet, despite the centrality of legitimacy to social scientific research in an array of areas and the presence of a common canon, there is little consensus surrounding how the construct should be operationalized. Legitimacy is routinely assessed using divergent indicators, including (among other things) measures of acceptance, obedience, support, and compliance with rules or norms (Jackson 2018; Risse and Stollenwerk 2018; Suchman 1995). The implications of these indicators differ to the extent that distinct approaches to operationalization have had the unintended consequence of fostering disparate understandings of legitimacy's meaning, causes, and effects (see Suddaby, Bitektine, and Haack 2017). Illustrating this point, research shows that people often comply with norms despite disapproving of them (Centola, Willer, and Macy 2005) or approve of behaviors that flagrantly violate social norms (Hahl, Kim, and Zuckerman Sivan 2018). Nevertheless, these (and other) distinct attitudes and behaviors are each used independently as direct indicators of the same construct. The net result is that legitimacy suffers the same fundamental problem as all indeterminate concepts: "We do not know when these 
concepts are empirically relevant and when they are not. Their meaning is primarily evocative" (Ermakoff 2017:130).

The purpose of this article is to render legitimacy determinate. Resolving indeterminacy requires clarifying a concept's definitional properties and identifying how these properties can be empirically traced (see Ermakoff 2015, 2017). I build on the well-documented literature on legitimacy in the social sciences to do just that. To be clear, I neither claim nor attempt to reinvent legitimacy or develop a novel definition. Rather, my goal is to discern common features of existing definitions of legitimacy and use these to identify properties of the construct that (1) are measurable and (2) distinguish legitimacy from related constructs.

Clarifying legitimacy's definitional properties to identify a common set of criteria for its measurement has methodological, theoretical, and substantive benefits. As Haack, Schilke, and Zucker (2021:751) succinctly put it, "theoretical and methodological choices necessarily coevolve" (see also Abbott 1988a; Breiger 2000; Greenwald 2012; Haack and Sieweke 2020). It is consequently unsurprising that, despite a remarkable degree of transdisciplinary dialogue in legitimacy research spanning the social sciences (see, e.g., Jackson 2018; Johnson et al. 2006; Mazerolle, Bennett, et al. 2013; Risse and Stollenwerk 2018; Suchman 1995; Suddaby et al. 2017; Zelditch 2001a), differences in how legitimacy is measured have both caused and exacerbated theoretical and substantive divisions (e.g., Baum and Powell 1995; Beetham [1991] 2013; Hannan et al. 1995; Pakulski 1986; Suddaby et al. 2017). Developing a synthetic approach to operationalization is thus a critical step toward realizing the potential for mutual learning within and across disciplines. Moreover, as I will detail, doing so stands to advance theoretical debates that have long seemed intractable and foster much-needed coherence in the accumulation of knowledge about legitimacy's causes and effects. 
I begin by comparing published review articles about legitimacy in criminology, law and society, organizational studies, psychology, political science, social psychology, and sociology. Using these reviews, I synthesize existing approaches to operationalization and identify definitional properties of legitimacy that are common across these areas of study. This review of the literature reveals that a key discrepancy between common approaches to operationalization is the unit of analysis, and that differences in the unit of analysis have significant theoretical ramifications. Bridging multiple approaches, I make the case that the appropriate unit of analysis for research on legitimacy is a dyad (i.e., two nodes and a tie), consisting of an object of legitimacy (the thing being evaluated), an audience (the source of evaluation), and a relationship that connects the two. As I will explain, the nodes in a dyad are not limited to individuals. Rather, a node can be any social entity, ranging from individuals or organizations to treaties or cultural objects (Pachucki and Breiger 2010).

With dyads as the empirical anchor, I outline a framework for operationalization that consists of three necessary conditions. Specifically, the presence or absence of legitimacy can be determined via the co-occurrence of expectations that define a relationship, assent to the relationship by the audience, and conformity to mutual expectations by the object of legitimacy. I delimit the scope of applicability for this operationalization and discuss how it advances important debates and resolves key challenges in the study of legitimacy.

After outlining the dyadic operationalization of legitimacy, I detail its implications for understanding legitimacy's effects. In short, by directing attention to whether legitimacy is present in a given dyad, this operationalization situates the effects of legitimacy within the dyad. Thus, rather than legitimacy affecting socially significant outcomes (e.g., stock prices, inequality, war onset) directly, it affects interaction between the object of legitimacy and an audience, which 
may (or, equally importantly, may not) affect other outcomes of interest. I discuss these implications and illustrate how they inform debates over the relevance of legitimacy in the context of the transdisciplinary field of revolutionary studies. I conclude by specifying concrete analytic steps for applying the dyadic model for operationalizing legitimacy.

\section{Conceptualizing Legitimacy}

In this section, I detail trends in how legitimacy is conceptualized and measured in the social sciences. I use eight reviews of the literature on legitimacy to identify (1) general approaches to operationalization, and (2) definitional properties of legitimacy that are common across the areas of study reviewed. ${ }^{1}$ All eight review articles were published between 1993 and 2018 (see Table 1). ${ }^{2}$ These reviews collectively account for 1,024 non-redundant works published since 1935. They synthesize substantive, ontological, and epistemological points of consensus and disagreement regarding how legitimacy is studied, invoked, and theorized. The reviews are written for distinct audiences in the social sciences (criminology, law and society, organizational studies, psychology, political science, social psychology, and sociology). ${ }^{3}$ The distinctiveness of the literatures these reviews account for is reflected in the fact that only 6.5 percent of all works cited are referenced in more than one review. ${ }^{4}$ Thus, although these reviews are by no means exhaustive of the vast collection of scholarship invoking legitimacy, they provide a reasonable basis for identifying patterns in research across time and disciplinary boundaries.

[Table 1 about here] 


\section{Common Approaches to Operationalizing Legitimacy}

I use the term operationalization to refer to the process of defining criteria for empirically measuring abstract constructs. To identify common criteria for legitimacy's measurement, I compiled and compared examples of measurement strategies featured in the eight review articles. As emphasized in the preceding section, there is a great deal of variation in how legitimacy is measured. Nevertheless, comparing across measurement strategies, I identified three general approaches to operationalization that are common across the disciplines reviewed.

These three approaches are distinguished by basic differences in the logic used to establish criteria for measuring legitimacy. It is important to note that although many measurement strategies align with only one of these general approaches, this is not always the case. Some scholars use composite indexes, elaborate different types of legitimacy, or account for multiple dimensions of the construct. In such cases, measurement strategies often include various indicators that align with more than one of the general approaches I identify. Consequently, the degree to which the specific measurement strategy used in a given study fits within one of these approaches to operationalization will vary.

The first general approach to operationalization establishes evidence of legitimacy via indicators of an audience's orientation toward an object of legitimacy. The logic of this approach is that legitimacy can be assessed by (1) identifying an entity or population that might render legitimacy judgments, and (2) assessing that population's assumptions, perceptions, or beliefs about the object, or about their relationship to the object. Measurement strategies that I classified under this approach routinely equate legitimacy with related constructs, such as trust, acceptance, support, consent, or perceived obligation to obey. Thus, the criterion for empirically establishing legitimacy is that one or more of these related constructs is present (e.g., law enforcement 
officers have legitimacy to the degree that people feel an obligation to obey their orders/consent to their authority). Examples of this approach can be found in literature reviewed by Johnson and colleagues (2006), Jackson (2018); Mazerolle, Bennett and colleagues (2013), Risse and Stollenwerk (2018), Suchman (1995), Suddaby and colleagues (2017), Tyler (2006), and Zelditch (2001a). ${ }^{5}$

The second general approach is to establish evidence of legitimacy via an alignment between the object of legitimacy and a given set of norms or expectations. Measurement associated with this approach (1) specifies a set of norms, values, or expectations, and (2) assesses whether the object of legitimacy conforms to those norms, values, or expectations. Among measurement strategies that I classify under this approach, some focus on the object's conformity to expectations as observed by the analyst, whereas others focus on conformity as perceived by those evaluating legitimacy. I refer to this distinction in measurement strategies as observed (by the analyst) versus perceived (by the source of legitimacy) alignment. ${ }^{6}$ It is important to emphasize that for analyses that center on perceived alignment, the empirical focus is on audiences' perceptions of whether the object of legitimacy conforms to certain standards, regardless of whether the audience trusts, supports, or is otherwise positively oriented toward the object itself (in contrast to the first approach to operationalization discussed). For measurement strategies associated with this general approach to operationalization, the criterion for empirically establishing legitimacy is that the object conforms (or is perceived to conform) with certain expectations. Examples of this approach to operationalization can be found in literature reviewed by Johnson and colleagues (2006), Jackson (2018); Mazerolle, Bennett and colleagues (2013), Risse and Stollenwerk (2018), Suchman (1995), Suddaby and colleagues (2017), and Tyler (2006). 
The third general approach is to establish legitimacy via indicators of awareness or recognition. Measurement strategies associated with this approach rely on indicators of the prevalence of an object of legitimacy, or lack of evident opposition to it. Associated with what scholars refer to as cognitive legitimacy, this approach views legitimacy as a collective orientation (Stryker 1994). Cognitive legitimacy is not based on whether an entity meets specific expectations, but on the "absence of questions about or challenges to an entity" (Tost 2011:692). Thus, for measurement strategies associated with this approach, the criterion for empirically establishing legitimacy is evidence that the object is treated as "necessary or inevitable based on some taken-for-granted cultural account” (Suchman 1995:582, emphasis in original). Examples of this approach can be found in literature reviewed by Johnson and colleagues (2006), Suchman (1995), Suddaby and colleagues (2017), Tyler (2006), and Zelditch (2001a). ${ }^{7}$

\section{Indeterminacy and the Unit of Analysis}

Each of these common approaches to establishing criteria for measuring legitimacy is grounded in theory and directly links measurement to definitional properties of the construct. Yet, there are theoretically consequential differences between these approaches to operationalization that are rooted in their units of analysis. Depending on whether legitimacy is measured via (1) individuals' orientations, (2) alignment between behavior and expectations, or (3) collective recognition/awareness, the unit of analysis varies between (i) individuals, (ii) the object of legitimacy, ${ }^{8}$ or (iii) fields/social environments.

Differences in the unit of analysis have exacerbated theoretical fragmentation. To illustrate, a common question spanning disciplinary and methodological traditions is: how does legitimacy occur? When individuals are the unit of analysis, researchers routinely use statistical 
methods and answer the question by assessing which conditions, on average, have the largest effect on legitimacy judgments across a predefined population (Jackson 2018; Mazerolle, Bennett, et al. 2013; Risse and Stollenwerk 2018; Tyler 2006). When the object of legitimacy defines the unit of analysis, research often focuses on how objects adapt to (or shape) the conditions of their environment (Suchman 1995; Suddaby et al. 2017). When the field/social environment is the unit of analysis, research routinely examines the emergence of expectations and how the criteria for legitimacy that are embedded in a social environment evolve over time (Johnson et al. 2006; Suchman 1995). These basic methodological artifacts guide theoretical developments, as research focused on individuals theorizes legitimacy as coming from external sources acting upon individuals, research focused on the object theorizes legitimacy as coming from the actions and attributes of the object, and research focused on the field/social environment theorizes legitimacy as coming from the dynamics of interaction within the field (see also Suddaby et al. 2017). These differences routinely render substantive and theoretical advances resulting from each approach incompatible with the others.

Differences in the unit of analysis are linked to differences in how legitimacy is conceptualized, with scholars defining legitimacy in a variety of ways, ranging from "the right to rule" (Risse and Stollenwerk 2018:404) to "the belief that [entities] are appropriate, proper, and just" (Tyler 2006:376). ${ }^{9}$ Seven of the review articles compare/contrast between two and seven definitions (mean $=3.86),{ }^{10}$ and six elaborate one or more theoretically consequential differences between these definitions (Jackson 2018; Johnson et al. 2006; Risse and Stollenwerk 2018; Suchman 1995; Suddaby et al. 2017; Tyler 2006). For example, in their meta-analysis of articles on legitimacy in management and organizational studies, Suddaby and colleagues (2017:451) 
advocate a single synthetic definition of legitimacy, but they elaborate three distinct approaches to legitimacy, "each of which betrays a unique epistemological and ontological position."

In the face of multiple conceptualizations of legitimacy, a popular approach to accounting for differences is to delineate types of legitimacy. Again, reinforcing the theoretical importance of the empirical referent, types of legitimacy are most clearly distinguished via the unit of analysis, with distinctions drawn based on (1) the source of legitimacy, (2) the object of legitimacy, or (3) the system of expectations used as a basis for evaluating legitimacy. Across the eight reviews, five identify at least two distinct types of legitimacy (Jackson 2018; Johnson et al. 2006; Risse and Stollenwerk 2018; Suchman 1995; Suddaby et al. 2017), and collectively they identify 25 different types of legitimacy (see Table 2). ${ }^{11}$ These legitimacy types function as heuristics, allowing researchers to account for empirical findings that cannot be explained with a unitary conception of legitimacy, such as observations that something is simultaneously legitimate (according to one type) and illegitimate (according to another). Consequently, legitimacy types are often used to establish scope conditions for empirical analyses, and to theoretically situate widely varying empirical referents for legitimacy. Yet, there are non-trivial inconsistencies in how these types are discussed and used. For example, normative legitimacy sometimes refers to prescriptive models that define what should be legitimate (Risse and Stollenwerk 2018), but other times it refers to normative evaluations by a particular audience and is treated as interchangeable with moral legitimacy (Johnson et al. 2006; Suchman 1995;

Suddaby et al. 2017). Such discrepancies in the meaning and implications of different types have further exacerbated theoretical and substantive fragmentation.

[Table 2 about here] 


\section{Definitional Properties of Legitimacy}

Despite showcasing inconsistencies in how legitimacy is conceptualized and measured, the eight reviews of legitimacy all treat the construct as implying a common meaning, and all identify common definitional properties of legitimacy. Summarizing their own review of legitimacy definitions, Johnson and colleagues (2006:57) observe that "all the definitions share fundamental similarities." This observation applies equally well when comparing across the eight review articles, and these similarities form the foundation for the operationalization I develop.

All the authors recognize that legitimacy involves positive perceptions or evaluations, which require an audience (this can be an individual, group, or corporate entity). ${ }^{12}$ All agree that legitimacy is conferred to a social object, such as an action, individual, institution, organization, or organizational form, among other things. All emphasize the centrality of social expectations that define the relationship between object and audience, whether those expectations are established via interaction (see e.g., Suddaby and colleagues' [2017] discussion of legitimacy-asprocess) or via "widely shared" (Suchman 1995:574) normative frameworks for evaluation (Risse and Stollenwerk 2018). Consequently, the reviews uniformly indicate that three empirical elements are necessary for legitimacy: an audience, an object of legitimacy, and a set of expectations that define the relationship between the two.

The reviews further show that these three empirical elements interact systematically. The object of legitimacy is the subject of audience evaluation, and audiences' evaluations are based on the object's conformity with expectations that define the relationship and are rooted in shared "norms, values, beliefs, or definitions" (Suchman 1995:574). Legitimacy thus implies that audiences are positively oriented toward an object of legitimacy based on mutual expectations to which the object conforms. 


\section{Empirically Anchoring Legitimacy: The Dyad as Unit of Analysis}

Given the theoretical consequences of adopting different units of analysis, as my point of departure for developing a synthetic operationalization of legitimacy, I address the question: what unit of analysis can simultaneously account for the three empirical elements (an object, an audience, and a set of social expectations) that are necessary for legitimacy without privileging one over the others?

The answer to this question, I contend, is the dyad. A dyad is a unitary entity composed of two nodes (e.g., individuals, groups, organizations, practices, cultural objects) and one or more relationships between them. ${ }^{13}$ Intuitive examples of dyads include romantic couples, patrons and clients, or mentors and mentees, but dyads can also include corporate nodes—such as countries, organizations, government agencies, political administrations, and any combination thereof_-or cultural objects, such as texts or treaties (see Pachucki and Breiger 2010).

Wasserman and Faust (1994:18) define dyads as "a pair of [nodes] and the (possible) tie(s) between them. ... The tie is inherently a property of the pair and therefore is not thought of as pertaining simply to an individual [node].”

A focus on dyads as the unit of analysis reconciles the paradoxical observation that legitimacy is simultaneously a "reaction of observers" and "possessed objectively" by the object of legitimacy (Suchman 1995:574). Rather than legitimacy being anchored to one node or the other, legitimacy can be understood as a property of the dyad as a whole. To illustrate, we cannot meaningfully analyze the legitimacy of a political regime (object) without reference to the source of legitimacy (audience), because the legitimacy of regimes is evaluated on demonstrably different terms by their subjects, other regimes, international governmental organizations, transnational organizations, and social movements (Beck 2014; Duyvesteyn 2017; Hafner- 
Burton and Tsutsui 2005). Consequently, we can only speak of legitimacy as it exists in a specific dyad, not the legitimacy of an object itself.

Dyads empirically account for the social expectations that structure legitimacy via the relationship (i.e., tie) that connects two nodes. Social expectations are a definitional feature of this relationship. Building on Weber's ([1921] 1978) definition of a social relationship as the probability that social action is predictable, Fuhse (2009:53) defines a tie in the context of dyads as "negotiated expectations and other . . . established forms of meaning." Consistent with the observation that legitimacy is determined in reference to some "socially constructed system of norms, values, beliefs, and definitions" (Suchman 1995:574; see also Johnson et al. 2006; Suddaby et al. 2017), the dyad is similarly defined in reference to mutual expectations.

As Simmel (1964:122) writes, although the dyad is "the simplest sociological form, methodologically speaking ... it contains the scheme, germ, and material of innumerable more complex forms." As detailed earlier, scholarship on legitimacy spans social science disciplines, and legitimacy research is conducted using diverse data collection methods. Consequently, any unit of analysis that is tailored to fit one methodology in particular risks simply compounding the existing logjam of approaches to operationalizing legitimacy. The simplicity of the dyad renders it compatible with the diverse methodologies applied in legitimacy research. Object, audience, and expectations can be specified and observed equally well via surveys, interviews, textual analysis, and observation, among other methods. However, the dyad can also capture the depth and contextual complexity associated with legitimacy and processes of legitimation (Jackson 2018; Johnson et al. 2006; Risse and Stollenwerk 2018; Suchman 1995; Suddaby et al. 2017; Tyler 2006). Social pressures, third-order beliefs, historical contingencies, institutional environments, normative assumptions, and many other contextual factors are all implicated in the 
constitution of each element of the dyad (Coleman 1994), and thus the unit as a whole.

Researchers account for these contextual factors when they identify or define the expectations that bind two nodes, when defining what constitutes an audience, and in identifying the object of legitimacy.

Because dyads can be defined a priori based on theoretical criteria or studied as emergent social forms (see Erikson 2013; White 2008), an empirical focus on dyads is as compatible with research examining how the structural composition of networks (i.e., triads and larger) influences the process of legitimation as it is with research examining the dynamics of legitimation in a particular place and time (e.g., Luft 2020). Moreover, legitimacy is often used as an explanans or explanandum for other constructs that involve collective evaluation, such as status and stigma. These constructs can be understood in dyadic terms equally well, thus facilitating research on their relationship to legitimacy via a common unit of analysis. Consequently, for the purpose of developing a generalizable operationalization of legitimacy, dyads impose few analytic constraints while being capable of representing the "scheme, germ, and material" of the many complex forms addressed in legitimacy research.

\section{Defining the Elements of the Dyad}

Before developing an operationalization that builds on dyads as the unit of analysis, it is necessary to define the elements of the dyad. These elements may be self-evident in research where individuals are the nodes, but it can be less clear when nodes are populations, collectives, or corporate entities.

Elements of a dyad are defined in relation to one another. We cannot define a tie without first identifying what is connected; any number of objects or entities can constitute a node in a 
dyad (Wasserman and Faust 1994), but nodes themselves are defined by the actual or possible occurrence of a tie between them (White 2008). Operationalizing each component of the dyad therefore requires reference to the other components. I begin by discussing the operationalization of the object and audience. Because expectations are implicated in both the empirical components of the unit of analysis (i.e., the tie) and the conditions for legitimacy (as I will elaborate), I address the measurement of expectations in the next section.

Regarding the operationalization of an object, existing scholarship illustrates the breadth of possibilities for what might constitute an object of legitimacy and suggests no systematic limits. Researchers have examined the legitimacy of actions, behaviors, cultural objects, decisions, individuals, institutional structures, organizations, organizational forms, positions, social arrangements, and a variety of other social entities (for examples, see the review articles listed in Table 1). The reason for such diversity is that legitimacy in part represents alignment between an object and a set of expectations for that object. Consequently, any object for which expectations can be established - whether it is a work of art and the expectations associated with a particular genre (Alexander and Bowler 2021) or an organization and the expectations associated with a particular industry sector (Zuckerman 1999) — can be analyzed as an object of legitimacy. Thus, an object of legitimacy can be operationalized as any entity that is subject to social expectations.

Regarding the operationalization of audience, expectations again play a critical role. As the source of evaluation for legitimacy, research accounts for audiences ranging from individuals (see Zelditch [2001a] on propriety) to entire populations in a particular geographic region (Risse and Stollenwerk 2018). Something may be legitimate among a certain group of experts, according to members of a particular profession, or within a polity. What defines an audience is 
the presence of shared expectations. Therefore, an audience of legitimacy can be operationalized as an individual, or as any collection of individuals that shares a common set of expectations in reference to the object of legitimacy. Defined this way, analysts can specify an audience while accounting for discontinuities in predefined populations. For example, in social contexts defined by competition or contention (see Fligstein and McAdam 2012; Risse and Stollenwerk 2018), a predefined population (e.g., potential consumers of commercial products or the population of a country) may not share a common set of expectations for a particular object (e.g., a product or

government). Subpopulations that share distinct expectations are treated as distinct audiences. A focus on shared expectations makes it possible to analytically account for these differences.

Identifying the nature of the relationship that connects two nodes is synonymous with identifying the operative expectations that define legitimacy. Therefore, in the next section I address the measurement of relationships and expectations together.

\section{Operationalizing Legitimacy: Necessary Conditions}

Answering the question, "what is the appropriate unit of analysis?" provides an empirical anchor for identifying traceable definitional properties of legitimacy. As detailed earlier, legitimacy implies a particular relationship among the elements of the dyad. In this section, I specify how these relationships among components of the dyad can be empirically established via the interaction of three conditions that are observable in the dyad. I refer to these conditions as expectations, assent, and conformity. I define each of these conditions and provide examples of how they can be measured. Individually, each condition is necessary for legitimacy. In conjunction, they are sufficient for empirically establishing legitimacy's presence. 


\section{Expectations}

Once the object and audience have been identified, the next step in operationalizing legitimacy is to identify the operative expectations that bind the two nodes. These expectations simultaneously define the relationship between nodes and serve as the criteria for legitimacy. Expectations may be the product of institutional fields (DiMaggio and Powell 1983) and define the nature of symbolic capital (Bourdieu 1994). They may emerge via small group interaction (Walker and Willer 2014), be specific to highly localized contexts (Schoon 2014), or be widely shared in a particular social arena (Zuckerman 1999). Regardless, expectations are a necessary condition for legitimacy.

As briefly outlined earlier, expectations are embedded in the content of the relationship between two nodes (Fuhse 2009). Ties and the relationships they represent are constituted by the meanings associated with the relationship, and embedded in those meanings are expectations (see Pachucki and Breiger 2010). As Erikson (2013:227) writes, "the absence of meaning could easily be understood as the absence of a relationship — when you have no expectations or knowledge of another." White (2008:2-5) elaborates this point, using multiple real-world examples to articulate the notion that networks - which are constituted by routinized interaction among nodes - emerge out of efforts to mitigate uncertainties and establish expectations in a given social context. ${ }^{14}$ Thus, expectations are empirically traceable by identifying the content of the relationship between nodes in a dyad.

How do we identify the content of a given relationship? Existing scholarship provides a wealth of guidance. Approaches will differ in contexts where social roles are well established and relationships are defined via institutional structures, versus contexts where the meaning structure of relationships are emergent or in flux. In contexts where relationships are well 
established and largely stable, a robust knowledge of the system itself may be sufficient to evaluate the expectations that define a relationship. This is illustrated by Zuckerman's (1999) study of how organizational legitimacy affects firms' performance. Focusing on the relationships between securities analysts and publicly traded companies, Zuckerman details how securities analysts specialize in particular product categories, which companies are clearly associated with. The structure of mediated markets establishes the expectation that companies will receive coverage from the analysts who specialize in their product areas. As Zuckerman details, failure to receive coverage - regardless of whether that coverage is positive or negative-delegitimates a company. In contrast, coverage confers legitimacy. Because these expectations are industrywide, institutionally defined, and generally stable, a common set of expectations defines the relationships between securities analysts and companies.

In contexts where the meaning structure of relationships is emergent or in flux, researchers can use a variety of methods to measure expectations in a given relationship, including ethnography, interviews, textual analysis, historical analysis, and survey research. For example, in his analysis of the armed conflict between the Republic of Turkey and the Kurdistan Workers' Party (PKK), Schoon (2015) uses statements by leaders and representatives of the PKK to identify claims made by the group that establish behavioral expectations. He then uses statements made by allies and supporters of the PKK to determine which of these expectations were shared by each audience, thus delineating multiple dyads with distinct sets of expectations. Schoon incorporates documentary sources spanning nearly two decades and illustrates how researchers can trace the evolution of expectations over time and across multiple dyads.

Expectations can also be identified and examined deductively. Returning to the review articles on legitimacy, both Jackson (2018) and Mazerolle, Bennett, and colleagues (2013) 
highlight several survey-based studies that (1) define systems of expectations (e.g., conceptions of procedural justice) that might specify the relationship between an authority (i.e., the state, police, or other forms of law enforcement) and its subjects, then (2) use survey instruments to assess the extent to which those expectations are salient for the audience. Importantly, these surveys account only for the audience perspective. However, the mutuality of expectations between audience and object can be assessed by examining formal statements by authorities, such as laws, constitutions, or professional mandates, which define the parameters of their relationship. Moreover, for research that treats a population as a collective actor representing one node in a dyad, survey research can be used to better specify subpopulations with shared expectations, distinguishing them from other populations that may have different expectations of the authority (for an extended discussion, see Risse and Stollenwerk 2018).

Assent

The second necessary condition for legitimacy is assent: agreement with, approval, or support of a relationship by the audience. Consistent with the notion that legitimacy is in part a positive evaluation by an audience, for a dyad to be characterized by legitimacy there must be an indication that the audience views the relationship as "desirable, proper or appropriate" (Suchman 1995:574).

A focus on audiences' assent to the relationship — rather than to the object of legitimacy - is based on the observation that any audience can have multiple ties to a given object. Discussions of legitimacy judgments in existing literature often focus on perceptions and assumptions about the object itself, but this focus implies that the relationship between audience 
and object is unitary. In contrast, a focus on assent to the relationship is sensitive to the fact that multiple ties can connect the same two nodes.

There are many models for how to empirically observe assent (Beetham [1991] 2013; Jackson 2018; Johnson et al. 2006; Risse and Stollenwerk 2018; Tyler 2006). Survey research measuring approval, support, trust, or confidence offers one effective method of measurement. For example, in their research examining the effects of procedural justice on police legitimacy, Mazerolle, Antrobus, and colleagues (2013) solicit responses using a Likert scale where respondents rate their agreement with the statement, "my own feelings about what is right and wrong usually agree with the rules and laws enforced by police" to measure legitimacy. This question measures assent (i.e., agreement with laws) in reference to expectations that define the relationship (i.e., the laws that police enforce).

One can also observe assent using textual, discursive, and observational data. For example, in their analysis of the processes through which Slobodan Milošević rose to power in Serbia in the late 1980s, Ermakoff and Grdesic (2019) trace the legitimation of Milošević and the delegitimation of his predecessor through a key vote in the Presidium of the central committee of the Serbian League of Communists. Ermakoff and Grdesic demonstrate how this vote established the basis for a subsequent vote that led to the ouster of the standing president of the Serbian League of Communists, Stambolić. In this context, the legitimation of Milošević relied on the assent of the voting members of the Presidium, which is observable in historical records, including vote tallies. Similarly, returning to Schoon's (2015) research on legitimacy and the PKK, supporters provided direct statements explaining and justifying their support for the group, with specific reference to mutual expectations of the relationship. 
In some contexts, it may be possible to observe assent simply based on audiences' participation in the relationship. Returning to Zuckerman's (1999) research on mediated markets, securities analysis firms (the audience) necessarily opt into a relationship with publicly traded and owned companies as part of the institutionally defined system. Similarly, individuals who join a voluntary organization implicitly assent to a relationship with that organization.

However, inferring assent via participation or patterns of behavior requires evidence that the relationship is voluntary, with the audience consenting to the expectations that tie it to the object. In cases where consent cannot be established, assent cannot be inferred. Illustrating the importance of this point, Correll and colleagues (2017) develop a theory of status advantage to explain why rewards are distributed based on status (e.g., race, gender) rather than performance, even in ostensibly meritocratic systems. They focus on conditions where the allocation of resources is shaped by third-order beliefs (i.e., assumptions about what "most people" think). Correll and colleagues (2017:304) find people adhere to status beliefs "even when those status beliefs are illegitimate," clearly demonstrating that participation in a system of rewards distribution does not necessarily indicate assent and highlighting how such systems are perpetuated despite being illegitimate. Importantly, in instances where it is not possible to determine whether an audience assents to the relationship, legitimacy is not necessarily absent. Rather, it simply cannot be empirically distinguished from other constructs.

\section{Conformity}

The third necessary condition for legitimacy is conformity. A key definitional property of legitimacy is that the object is evaluated in relation to some system of expectations. For legitimacy to be present, the object must evidently conform to those expectations. To illustrate, 
researchers may determine that a community expects procedural justice in their interactions with police officers (Mazerolle, Bennett, et al. 2013). These expectations may be mutual, as indicated, for example, by official law-enforcement policies that specify appropriate procedures for interaction with civilians, and citizens often assent to police authority based on those expectations. Consequently, police actions are legitimate if they conform to those expectations but lack legitimacy when the expectations are evidently violated (see Jackson 2018). Similarly, neoinstitutionalist scholarship in organizational analysis views legitimacy as a direct result of conformity to collective norms and expectations embedded in institutional fields (i.e., isomorphism) (DiMaggio and Powell 1983). ${ }^{15}$

Studies that operationalize legitimacy as an alignment between the object of legitimacy and a set of expectations provide valuable models for measuring conformity. Consistent with my earlier discussion of measurement strategies associated with this approach to operationalization, conformity can be measured in two distinct ways: via observed or perceived alignment between the object and expectations. In both cases, existing scholarship again offers a wealth of guidance for how conformity can be assessed.

Regarding observed conformity, researchers can use observational, textual, or other documentary data to determine whether an object's actions, behaviors, or orientations conform to a particular set of expectations. For example, in their analysis of the legitimation of the field of "outsider art" (a field constituted by artists who "do not have formal training in artistic practice" and create art without apparent interest in rewards), Alexander and Bowler (2021) use historical documents and historiography to trace how the work of one vanguard artist was able to conform to the expectations (e.g., having exhibits in major museums and sales at a major auction house) that define legitimacy in the broader field of cultural production. 
Regarding perceived conformity, surveys, interviews, or text-based data collection, among other methods, can all be used to compile data on whether a given audience perceives the object of legitimacy as conforming with expectations. For example, in their analysis of normative beliefs about whether violence is an acceptable means of achieving social control, Jackson and colleagues (2013:496) capture police conformity when they ask interviewees to rate the extent to which they agree with statements such as, "police usually act in ways that are consistent with my ideas of what is right and wrong" and "police in my neighborhood always behave according to the law." These questions account for whether the behaviors of the object of legitimacy (the police) conform to audience expectations (ideas of right and wrong; the law).

Approaches to measuring and conceptualizing conformity account for the same definitional property of legitimacy (Tankebe 2013), but they can be decoupled when the audience has incomplete knowledge of the object's actions, behaviors, or orientations. We would expect, for instance, that in newly established dyads, an object's conformity to expectations may precede an audience's perceptions of conformity, or vice versa. In either case, perceived/actual conformity can produce legitimacy, thereby encouraging actual/perceived conformity (respectively) and further reinforcing legitimacy. To illustrate, in evaluating the legitimacy of a treaty or some other international legal accord, we can observe whether the enactment of the treaty conforms to the expectations established in its texts and agreed to by the signatories. However, the treaty can benefit from legitimacy (to the relevant audiences) prior to its formal enactment if the process of negotiating the treaty produces perceptions that the enactment of the treaty will conform to expectations. These perceptions may then increase the likelihood that the treaty's enactment will observably conform to expectations. 
It is also possible for perceptions of conformity to be present despite the object directly violating expectations, so long as the violations are masked (Zelditch and Walker 2003). In these instances, legitimacy is fragile and risks deterioration if the decoupling is unmasked.

Importantly, however, one implication of legitimacy is that it can allow the object to deviate from expectations without undermining the stability of the dyad (LaFree and Morris 2012; Ridgeway 2011). This is most salient when the object itself endures over time (e.g., when the object is an individual, organization, institution, or some other durable social form), but is less salient when evaluating the legitimacy of a particular act (e.g., an act of violence). For enduring social objects, the effects of legitimacy are assumed to be similar to the effects of good faith or trust, implying something beyond a transactional relationship. Thus, if decoupling between perceived and actual conformity becomes evident but is episodic and can be appropriately justified, it does not necessarily undermine the relationship when conformity is the norm.

I detail these possibilities to emphasize four practical considerations when assessing conformity: (1) the two approaches to measurement account for the same definitional property of legitimacy; (2) the empirical dynamics accounted for by each approach can nevertheless be decoupled; (3) evidence of decoupling should prompt investigation into its causes and consequences; and (4) each of the preceding considerations point to the importance of accounting for the temporality of the dyad and of what researchers are able to observe within the dyad.

Finally, it is important to emphasize that perceived conformity cannot simply be assessed using measures designed to account for assent. Conformity can encourage assent (e.g., objects might change their behaviors to build support), and assent can foster conformity (e.g., leaders might work to fulfill the expectations of those who already support them), but the two can operate independently. To illustrate, consider a presidential administration that violates existing 
laws, but enforces those laws when others violate them, and their constituents continue to support or approve of the laws on the books. In this example, we see an absence of conformity to mutual expectations coupled with assent to those expectations. The reverse can also occur, where a regime conforms to existing laws, but their constituents do not assent to a relationship based on those laws, as is often the case during episodes of political contention, such as intrastate armed conflict (Duyvesteyn 2017).

\section{A Dyadic Operationalization of Legitimacy}

To measure legitimacy, we need to identify the components of the dyad (object, audience, expectations). Once the unit of analysis is clearly specified, we must then establish that the three necessary conditions are met. The co-occurrence of these three conditions is sufficient for empirically establishing legitimacy's presence. Expectations establish the nature of the relationship and provide the basis for evaluating the presence of assent and conformity. Assent establishes audiences' positive orientation toward the relationship. Conformity establishes that the object of legitimacy aligns with the expectations that define the parameters of evaluation. These conditions are general enough that they are amenable to measurement across the diverse methodological traditions represented in legitimacy research, but specific enough that they capture the definitional properties of legitimacy that are common across these traditions. Equally important, these conditions are observable within a unit of analysis that simultaneously accounts for each empirical component that is theoretically implied by definitions of legitimacy featured in the review articles discussed earlier. Mapped onto the empirical components, these conditions provide a framework for measuring legitimacy, as represented in Figure 1. 
[Figure 1 about here]

Why is the co-occurrence of these conditions sufficient for empirically establishing legitimacy? There is widespread agreement that legitimacy is a multidimensional construct (Jackson 2018; Johnson et al. 2006; Mazerolle, Bennett, et al. 2013; Risse and Stollenwerk 2018; Suchman 1995; Suddaby et al. 2017; Tyler 2006; Zelditch 2001a). Each of these conditions captures a distinct dimension of legitimacy that is found in existing approaches to measurement. However, any condition in isolation may indicate something other than legitimacy. For example, shared expectations, absent evidence of assent, may indicate "illegitimate" third-order beliefs (Correll et al. 2017:304), as reflected in gender or racial biases that undergird pervasive systems of oppression (see, e.g., Ray 2019). Similarly, assent absent clear expectations or conformity to established expectations may be evidence of a crisis of legitimacy rather than legitimacy itself (Hahl et al. 2018). Moreover, conformity with certain expectations absent evidence of assent to those expectations risks empirically conflating legitimacy with tolerance or acquiescence (Beetham [1991] 2013; Kurzman 2004; Pakulski 1986). An inability to establish all three necessary conditions does not mean legitimacy is absent. Rather, it leaves open the possibility that researchers are measuring phenomena quite different from legitimacy. In contrast, the cooccurrence of all three conditions allows researchers to rule out explanations other than legitimacy for the occurrence of any one condition in isolation.

Beyond disentangling legitimacy from phenomena that might empirically appear similar, this approach to operationalization allows analysts to account for the relativity of legitimacy, and for degrees of variation in its evaluation. In many cases, two objects of legitimacy may be subject to evaluation by the same audience based on a common set of expectations. Examples of 
this scenario include evaluations of competing political regimes by a territorially defined population (Kurzman 2004), the legitimacy of organizations in a common market (Zuckerman 1999), or the legitimacy of competing candidates vying for leadership (Schoon and West 2018). Relationships often involve multiple expectations (e.g., many people expect a government to provide basic public services and uphold civil liberties). Accounting for multiple expectations in a given relationship, researchers can assess degrees of legitimacy by evaluating the extent to which all expectations are being met. This also allows for comparison, such that one object might benefit from greater legitimacy than another in their relationship with a common audience.

This operationalization of legitimacy is also scalable. Because nodes can be either individual or collective, this framework can be used to empirically trace legitimacy in contexts ranging from small group processes - such as the establishment of informal status hierarchiesto macro-historical events—-such as the legitimacy of regimes or revolutionary actors.

\section{Accounting for Illegitimacy}

This operationalization is also capable of accounting for illegitimacy. Existing research adopts two distinct approaches to conceptualizing illegitimacy. One treats illegitimacy as simply the absence of legitimacy; the other defines illegitimacy as an independent construct (see Beetham [1991] 2013; Schoon 2014, 2016). The dyadic operationalization can be applied equally well to both.

First, conceiving of illegitimacy as the absence of legitimacy implies that the absence of assent or conformity would indicate illegitimacy. If the object fails to conform to expectations, or the audience does not assent to a relationship with the object, then legitimacy is absent from the dyad, and the dyad is therefore characterized by illegitimacy. Importantly, expectations must still 
be present because some type of relationship must exist for legitimacy or illegitimacy to be analyzed. Without expectations, there is no relationship (Erikson 2013), and without a relationship, legitimacy and illegitimacy are irrelevant.

Second, treating illegitimacy as an independent construct (i.e., more than the mere absence of legitimacy) implies a more specific, but still wholly observable, set of conditions. To elaborate, I use Beetham's ([1991] 2013) conceptualization of illegitimacy as a model. Beetham defines illegitimacy as a breach of the rules that define legitimacy. He distinguishes illegitimacy from two other conditions: a legitimacy deficit (in his framework, this describes a discrepancy between rules and beliefs), and delegitimation (a "withdrawal of consent") (Beetham [1991] 2013:20). Beetham ([1991] 2013:16) writes, "power is illegitimate where it is either acquired in contravention of the rules (expropriation, usurpation, coup d'état) or exercised in a manner that contravenes or exceeds them." Using Beetham's definition, illegitimacy is observable if an object fails or refuses to conform to expectations. For this to constitute illegitimacy, the expectations would nevertheless have to remain mutual, and assent to a relationship based on those expectations must be present. To illustrate, if a workplace establishes the expectation that promotions will be based on merit, workers accept those expectations, and those with the power to make promotions reinforce those expectations, then promotions that violate meritocratic expectations would be illegitimate (Castilla and Benard 2010).

The dyadic model can also be used to account for the two other negative conditions that Beetham describes: a legitimacy deficit, or delegitimation. A legitimacy deficit would be indicated by a disjuncture between the expectations of the audience and the expectations of the object, as long as both nodes sought to maintain the relationship and assented/conformed to their own understanding of the expectations that define the relationship (even if each node's 
expectations substantively differ). Similarly, delegitimation would be indicated by the withdrawal of assent on the part of the audience.

\section{Limits and Implications}

This operationalization reflects the definitional properties of legitimacy that are common across fields of study, but it is conspicuously incompatible with research that theorizes legitimacy exclusively as a cognitive orientation. As detailed earlier, cognitive legitimacy_one of the most commonly referenced types among those listed in Table 2-assumes an object is legitimate if it is treated as necessary or inevitable (Suchman 1995). As Tost (2011) observes, cognitive legitimacy represents the absence of evaluation. In the terminology of the dyadic operationalization, this means an absence of assent. Cognitive legitimacy thus definitionally precludes one of the three necessary conditions for legitimacy. Therefore, the dyadic operationalization is incompatible with cognitive legitimacy, and with other approaches where legitimacy is conceptualized as occurring independent of audience evaluation (see Tost 2011).

This incompatibility delimits the scope of application for the dyadic operationalization, but it also points to ways the operationalization stands to advance substantive and theoretical scholarship. At a basic level, it provides a clear framework for evaluating the relationship between distinct approaches to conceptualizing and studying legitimacy. For example, the delineation of legitimacy types is a key feature of substantive and theoretical advances across many fields of research, but the degree to which the "over proliferation of types" (Suddaby et al. 2017:454) represent theoretically consequential differences versus substantive distinctions is often unclear. As the incompatibility with cognitive legitimacy illustrates, specifying necessary 
conditions that transcend disciplinary boundaries provides a basis for determining which types represent a shared understanding of legitimacy, and how they differ when they do not.

Identifying such sources of conceptual division is important for advancing theoretical debates. As a case in point, in political analysis, an inability to distinguish legitimacy from tolerance or acquiescence anchors important theoretical critiques (e.g., Beetham [1991] 2013; Kurzman 2004; Pakulski 1986) and motivates some scholars to argue against the utility of legitimacy as an analytic construct (e.g., Marquez 2016; O'Kane 1993; cf. Gilley 2009). However, this distinction is captured by the dyadic operationalization through the measurement of assent. Thus, these critiques can be situated vis-à-vis research where assent is absent, unmeasured, or unmeasurable (e.g., research on cognitive legitimacy). This clarification helps shift the debates away from epistemological divisions over the explanatory value of legitimacy, and toward questions of methodology, where common ground may be more likely.

In addition to advancing definitional and theoretical debates, application of the dyadic operationalization has the potential to be theoretically generative for research in multiple areas. For example, extensive research has examined the legitimation of status-based inequalities (Johnson et al. 2006), such as gendered inequalities in hiring and promotion (Correll et al. 2017; Ridgeway and Correll 2006). Building on the observation that cognitive orientations (validity) and personal belief (propriety) vary independently (Johnson et al. 2006; Zelditch 2001a), research shows that common assumptions about status characteristics can validate inequalities (Ridgeway 2001). Status inequalities "appear to participants to be socially accepted and consensual ... [they are] accepted by others as a valid social fact. ... [Once this occurs,] status beliefs become very difficult to challenge on any broad-based scale in society" (Johnson et al. 2006:62-63). Validation relies on a perceived consensus among members of a population about 
status characteristics, such that status beliefs govern behavior regardless of whether a subset of the population disagrees.

Because the dyadic operationalization treats the subset of the population that holds distinct expectations about the nature of rewards distributions (e.g., hiring and promotion) as a distinct audience, even status beliefs that govern the behavior of an entire population are not assumed to operate uniformly across all audiences within that population. Empirically parsing dyads within a population and looking at patterns of association between those audiences paves the way for testing assumptions about the robustness of social validation and the role of legitimacy in changing status inequalities. For example, based on research on third-order beliefs (Centola et al. 2005), we should expect the structure of networks that connect audiences will mediate (1) the extent to which validity and propriety vary independently, and (2) the extent to which legitimacy in one dyad is affected by the expectations that define another. Accounting for differences in each audience's relationship to a common object of legitimacy, and their relationship to one another, allows researchers to test these possibilities and develop more specific predictions than research where the audience is treated as unitary. Doing this has substantive implications for assessing the role of legitimacy in fomenting social change, particularly considering research showing that proactive steps by a subset of a workplace can mitigate status inequalities, even in the face of opposition by others (Correll 2017).

Organizational research has grappled with similar questions about the generalizability of validity, with recent scholarship emphasizing the diversity of actors and expectations that characterize organizational fields ${ }^{16}$ (e.g., Fligstein and McAdam 2012). As Haack and colleagues (2021:2) observe, "the longstanding practice of equating legitimacy with collective agreement has impaired scholars' capacity to theorize the precise legitimacy processes that precede 
institutional change and has stalled intellectual progress in this core area of organizational research." The dyadic operationalization aligns theoretically and methodologically with recommendations for how to address this impediment, and again provides clear criteria for measuring the "intricate interactions" (Haack et al. 2021:3) that characterize legitimacy in observational studies.

Many researchers have advocated a focus on legitimation rather than studying legitimacy as a static state (see Johnson et al. 2006; Suddaby et al. 2017), and the dyadic operationalization is equally valuable for research on legitimacy processes. Theoretical advances in the study of legitimation tend to center on identifying stages in the processes whereby legitimacy is constructed, and objects are construed as legitimate. Research in this vein advances the view that legitimation is the subject of continuous negotiation, where legitimacy is embedded in interactions that emerge and evolve over time (Johnson et al. 2006). However, efforts to identify stages of legitimation often reflect the same patterns as other veins of legitimacy research, focusing on the conditions that shape audience perceptions, strategies of alignment adopted by objects, or the emergence of novel expectations (Suddaby et al. 2017). A dyadic operationalization brings these elements together in empirical analyses. Doing so helps specify scope conditions for theories of legitimation. It requires explicit identification of whether a theory accounts for change in elements of the dyad or the necessary conditions, and which elements of the dyad or necessary conditions are presumed to change. This encourages researchers to account for the theoretical implications of assuming that one or two elements of the dyad or one or two necessary conditions are stable. Moreover, the dyad provides a logical point of departure for advancing system-oriented approaches (Abbott 1988b) to the study of 
legitimation by examining how dyadic interactions between a specific audience and object are mediated by multimodal networks underlying a social field (Singh 2016).

Finally, the dyadic operationalization of legitimacy provides a general groundwork for studying how networks shape the establishment and effects of legitimacy. Among other important insights, research shows expectations and beliefs diffuse through social networks (Centola 2015), and power imbalances within a network can indirectly influence interactions in individual dyads (Molm 2006). Considering the emphasis in legitimacy research on understanding both the causes and effects of legitimacy, these findings from other areas of scholarship point to important directions for future legitimacy research. Thus, the dyadic operationalization paves the way for the application of methods and theoretical models not typically incorporated into legitimacy research, but which can further inform our understanding of legitimacy.

\section{Legitimacy's Effects}

Given the tight coupling between methods and theory (Abbott 1988a; Breiger 2000; Greenwald 2012; Haack et al. 2021), the operationalization developed here is not theoretically neutral. I chose to focus on points of consensus across various approaches to defining and conceptualizing legitimacy rather than emphasizing the elements that make each approach distinct. I made implicit aspects of some approaches to legitimacy explicit and prioritized equally weighting the three empirical components necessary for legitimacy. Each of these decisions have downstream implications for theorizing the effects of legitimacy.

Situating the measurement of legitimacy in dyads eschews the notion that an object can be legitimate in the sense implied by an essentialist ontology. In his manifesto for relational 
sociology, Emirbayer (1997) contrasts what he refers to as relational versus substantialist approaches to social research to highlight a critical distinction between an orientation toward relationships and processes versus an orientation toward attributes and entities, respectively. Emirbayer (1997:308) details how a substantialist approach adopts an essentialist model that treats objects as "possessing singular, unitary 'identities.",

Legitimacy is often discussed and operationalized in substantialist terms as something an object is or has (see Jackson 2018; Johnson et al. 2006; Risse and Stollenwerk 2018; Suddaby et al. 2017). This has an intuitive appeal for researchers interested in exploring legitimacy's effects. Treating legitimacy as an attribute or property allows researchers to identify indicators of legitimacy and examine the relationship between those indicators and an outcome of interest. In doing so, legitimacy can be incorporated into various explanatory frameworks, and its causal importance can be compared with other (often material or structural) conditions. In contrast, applying the dyadic operationalization allows for the possibility that any object or audience can be part of multiple dyads at the same time. Thus, certain dyads can be characterized by legitimacy such that an object benefits from legitimacy in a particular dyad but cannot possess legitimacy as a property or attribute.

Consequently, a key implication of the dyadic operationalization is that the direct effects of legitimacy are limited to the dyad. In other words, legitimacy has only an indirect effect on outcomes exogenous to the dyad. Among other outcomes, legitimacy has been invoked to explain the stability, support, or success of various social objects (see Schoon, Joosse, and Milward 2020). The implication that an object cannot simply be legitimate implies that legitimacy does not act as an independent variable that affects outcomes for the object. If legitimacy influences stability, it influences the stability of the dyad. If legitimacy fosters 
support, it fosters support of the object by the audience in the dyad. The extent to which legitimacy influences an outcome for the object—such as a company's stock prices, funding for the police, or the persistence of status hierarchies - is entirely dependent on the extent to which the nodes in a particular dyad are capable of influencing those outcomes.

\section{Illustrating the Implications: Legitimacy and Revolutions}

Shifting attention to how legitimacy affects dyads rather than exogenous outcomes for the object of legitimacy has both substantive and theoretical payoffs. To illustrate, I turn to debates over the causal relevance of legitimacy in the transdisciplinary field of revolutionary studies. Over the past century, four distinct generations of revolutionary studies have emerged, each of which is defined by different theories, notions of causality, and logics of explanation (Goldstone 2001). Each successive generation is marked by broad points of consensus (Lawson 2016), but questions surrounding the role of legitimacy in revolution have persisted across generations (Beck 2017). Many scholars highlight legitimacy (its loss, or contestation) in explanations of revolution (e.g., Beck 2014; Goldstone 2001; Sharman 2003; Zelditch and Walker 2003). Even when legitimacy is not theoretically central, it remains a persistent theme. When explaining specific cases or historical episodes, scholars invoke the legitimation of resistance (Goodwin 2001), efforts to strip regimes of their legitimacy (Nepstad 2011), precipitous declines in a leader's legitimacy (Chenoweth and Stephan 2011), the maintenance of legitimacy (Beck 2014), or the destabilization of state legitimacy (Lawson 2016).

Yet, influential scholars in this field have argued that legitimacy provides little explanatory leverage, pointing to the fact that "history is full of numerous examples of regimes that were believed to be popularly illegitimate but persisted" (Beck 2017:181). Some simply 
contend that legitimacy-based explanations are inadequate because they fail to account for key material factors (e.g., Goldstone 1991), but others raise more serious concerns about the nature of legitimacy's effects. These critiques are encapsulated in two prominent works that are emblematic of the third and fourth generations of revolutionary studies, respectively (see Lawson 2016): Theda Skocpol's (1979) States and Social Revolutions and Charles Kurzman's (2004) The Unthinkable Revolution in Iran.

Addressing prior explanations of social revolution, Skocpol (1979:32) critiques legitimacy-based explanations on structuralist grounds: "Even after great loss of legitimacy has occurred, a state can remain quite stable — and certainly invulnerable to internal mass-based revolts - especially if its coercive organizations remain coherent and effective." However, Skocpol (1979:32) offers a caveat, observing that "what matters most is always the support or acquiescence not of the popular majority of society but of the politically powerful and mobilized groups, invariably including the regime's own cadres." This notion that it is elites and the politically active (rather than the general population) who matter most for revolutionary onset is echoed by others (e.g., Sharman 2003). As Skocpol (1979:32) writes, “The ebbing of a regime's legitimacy in the eyes of its own cadres and other politically powerful groups may figure as a mediating variable in an analysis of regime breakdown." Her critique thus leaves room for the possibility that legitimacy matters, but only under specific conditions that prior work does not analytically capture.

In his analysis of the Iranian Revolution of 1979, Kurzman (2004:136) offers a different but equally pointed critique of legitimacy-based explanations: "The Pahlavi regime is sometimes said to have lost 'legitimacy,' as though this were an explanation for the Shah's fall." He argues that legitimacy is not some fixed property that can simply be lost or gained. Drawing a parallel 
between the effects of legitimacy and the effects of economic performance on revolutionary onset, Kurzman (2004:136) writes, “it's not that a regime delivers or fails to deliver a particular level of growth, but that a different regime would have done 'better' - a counterfactual whose attractiveness rises and falls independent of the current regime's actual economic performance." Focusing on the relationality of revolutionary processes, he argues that what prompts participation in revolution is not the regime losing legitimacy, but popular perceptions that a viable alternative exists.

These critiques are damning from a substantialist perspective, but they highlight the value of adopting the dyadic operationalization. In Skocpol's case, her primary contention is that legitimacy functions as a mediating variable, and she points to differences in the effects of legitimacy in the eyes of some audiences versus others. The argument that legitimacy has a mediating effect is fully consistent with the notion that legitimacy affects the dyad and does not directly affect outcomes such as revolution. Similarly, her observation that some audiences matter more than others implies a relational logic that is fully consistent with the dyadic approach advanced here. Consequently, based on her assessment that (1) legitimacy can affect the relationship between elites and a regime, and (2) a loss of legitimacy in that relationship may be causally relevant for the onset of social revolution, Skocpol's critique can be productively understood as a problem of measurement. By operationalizing legitimacy dyadically, its effects can be measured as they are theorized, providing a framework for assessing how legitimacy mediates - rather than supplants - other causes of revolution.

Turning to Kurzman's assertion that legitimacy is not simply a property that is present or absent, the dyadic operationalization again provides a basis for assessing the role of legitimacy in a way that aligns with the core of this argument. As Kurzman contends, the effects of legitimacy 
are contingent on peoples' perception that an alternative is viable. It is not simply that one regime loses legitimacy, but that people assent to a different regime altogether. A benefit of the dyadic operationalization is that it allows analysts to account for this relationality. Here again, a dyadic approach situates legitimacy's effects in a way that is consistent with Kurzman's argument that a loss of legitimacy does not directly affect the onset of popular revolution, while making it possible to examine when and how legitimacy does matter, as other scholars have argued is the case.

The specifics of these examples are rooted in revolutionary studies. However, they are indicative of a broader set of theoretical concerns. They illustrate how the dyadic operationalization can help address questions surrounding the explanatory relevance of legitimacy, the conditions under which legitimacy matters, and questions of how legitimacy affects important social outcomes, all of which span the social sciences.

\section{Applying the Dyadic Model for Operationalizing Legitimacy}

Through the preceding discussion, I have developed the theoretical foundations, justifications, and implications of a synthetic set of criteria for empirically measuring legitimacy with dyads as the unit of analysis. The resulting framework implies five concrete analytic steps for applying the dyadic model for operationalizing legitimacy:

1. Identify the object and audience of legitimacy (i.e., the nodes of the dyad). When analyzing or discussing legitimacy, researchers should clearly and explicitly specify what/who is the object of legitimacy, and who is the evaluating audience.

2. Specify the relationship of interest between the two nodes. Once two nodes are identified, researchers must determine the relationship of interest between them. Two nodes can 
have multiple relationships that are analytically distinct (e.g., a worker and a supervisor may have an employment relationship but may also be friends or romantic partners). In such instances, analysts must specify which relationship(s) are analytically relevant, as each relationship may be associated with distinct expectations.

3. Identify the expectations that define the relationship. Once the unit of analysis (i.e., the dyad) is clearly specified, the researcher must identify what expectations define the relationship. In doing this, analysts should consider whether social roles are well established and relationships are defined via institutional structures, versus emergent or in flux. For the former, researchers may look to the structure of the broader field/social environment to identify expectations; for the latter, researchers must account for relational dynamics specific to the individual dyad. In this process, it is important to consider both the temporality of the expectations (i.e., how they emerge/evolve) and how they are shaped by contextual factors embedded in the broader social field.

4. Establish empirical evidence of assent. Once the expectations that define the relationship are identified, it is necessary to empirically assess whether the audience agrees with, approves of, or supports their relationship with the object, as defined by those expectations. Methods for measuring assent will vary based on the nature of the audience (e.g., individuals, populations, organizations, states). However, evidence of a positive orientation is necessary for distinguishing legitimacy from conditions of coercion or conditional tolerance.

5. Establish empirical evidence of conformity. For the dyad to be characterized by legitimacy, there must be evidence that the object conforms to the expectations that define the relationship. Researchers may focus on observed or perceived conformity, and 
while allowing for the likelihood the two are tightly coupled, should be sensitive to the possibility they are decoupled. If they are decoupled, researchers must account for the nature of the decoupling and its implications for understanding legitimacy's effects.

How researchers accomplish each of these steps will differ depending on the nature of their data and their research design. Throughout this discussion, I have given examples of how some common measurement strategies can be used to establish each of the criteria referenced in these steps. Because the dyadic model builds on points of consensus in the literature on legitimacy and integrates existing approaches to measurement, it will often be possible to accomplish these steps with minimal adjustments to common research designs. For example, legitimacy research that relies on survey responses often uses composite indexes composed of multiple survey questions to measure legitimacy. These indexes routinely include questions that capture both assent and perceived conformity. Because the nodes are typically predefined (i.e., a surveyed population and a particular object) and expectations (i.e., the relationships of interest) are established by the researcher, researchers need only construct distinct indexes capable of accounting for assent and conformity independently. Doing so allows the researcher to assess whether assent and conformity co-occur (indicating legitimacy) or not (potentially indicating something else).

In other cases, adopting the dyadic model may require larger adjustments, such as collecting additional data or making changes to the research design. For example, research that measures legitimacy exclusively based on whether an object aligns with diffuse expectations will need to clearly identify an audience that holds those expectations and determine whether they assent to the relationship. The latter requirement may not be challenging (if asked, most 
researchers can likely identify the audience of interest), but measuring assent may necessitate collecting additional data or different types of data than what was collected to assess conformity. In such cases, the analytic specificity required by the dyadic operationalization may be more challenging to achieve. However, the rewards for this analytic specificity are greater theoretical clarity, empirical comparability, and a robust foundation for knowledge accumulation.

\section{Conclusion}

To know when legitimacy is relevant, we must first be able to determine when it is present. To understand how legitimacy emerges, or how it affects social processes, we must first be able to distinguish it from other constructs that appear similar or represent competing explanations. The dyadic operationalization developed in this article accomplishes these tasks by building on points of consensus in social scientific accounts of legitimacy to establish criteria for its empirical measurement. These criteria can be observed using multiple methods-ranging from surveys to discourse analysis - and multiple research designs, from experiments to historical research. In this way, the dyadic operationalization stands to bridge the conceptual divides that have emerged as an unintended byproduct of methodological diversity in the study of legitimacy.

Research on legitimacy spans the social sciences, and legitimacy is implicated in a variety of debates that are specific to various fields of study. Consequently, the value added by this operationalization will vary from one field to the next. For some, having clearly delineated criteria for distinguishing legitimacy from other constructs stands to advance long-standing debates. For others, this operationalization offers a concrete basis for integrating insights from research in different areas, making it possible to develop more accurate predictions about the 
effects of legitimacy, better specify and test the conditions under which validity may be undermined, or more clearly identify legitimacy processes. Thus, while theories of legitimacy, approaches to measurement, and substantive debates vary widely, this article introduces a framework for operationalization that is applicable across these various arenas and has the potential to facilitate meaningful advances in legitimacy research.

\section{Notes}

1. I used NVivo to code the reviews and compare approaches to operationalizing and defining legitimacy.

2. In selecting reviews, I included articles that had the sole purpose of reviewing literature on legitimacy without attempting to advance a distinct empirical contribution. I further focused on reviews that were published in the 25 years prior to the start of this work.

3. Two of these reviews were written for organizational studies (the same disciplinary audience): Suchman (1995) and Suddaby and colleagues (2017). I included both reviews because they account for unique scholarship in this area. Suchman's (1995) article is the most widely cited review article on legitimacy, with more than 20,000 citations as of this writing, and continues to be highly cited (in 2020 alone, Google Scholar recorded 1,910 citations of this article). This level of influence warranted its inclusion. However, it is also the earliest review included, and Suddaby and colleagues (2017) account for important developments since its publication. The rate of overlap in works cited by these two reviews is only 8.8 percent, indicating that each work makes unique contributions in synthesizing scholarship on legitimacy.

4. Of the 1,024 unique works cited, only 67 were cited by two or more reviews. 
5. Zelditch (2001a) and others (Johnson et al. 2006; Suddaby et al. 2017) explicitly distinguish between individuals' beliefs (propriety) and collective orientations (validity) as dual components of legitimacy. Here I associate measurements of propriety_-"a particular individual's personal belief that an act, norm, value, belief, practice or procedure is right" (Zelditch 2001a:6) — with this approach to operationalization.

6. Tankebe (2013; cited by Jackson 2018) provides a useful discussion of this distinction in his analysis of police legitimacy, referring to them as "objective" and "subjective" approaches to measurement.

7. Following Stryker (1994), I classify measurements of validity_-"a collective consensus that observably governs the behavior of . . the members of a collectivity" (Zelditch 2001a:6) — with this approach to operationalization.

8. This is the case when analyses rely on observed alignment. However, when researchers focus on perceived alignment, the unit of analysis is typically individuals. Nevertheless, both approaches to measuring alignment are consistent with the epistemological perspective that Suddaby and colleagues (2017) refer to as legitimacy-as-property (i.e., as a property of the object), which theoretically privileges the object of legitimacy as opposed to the audience or social field.

9. Notably, both Risse and Stollenwerk (2018) and Tyler (2006) build explicitly on Weber's writings to define legitimacy.

10. Zelditch (2001a) does not provide an explicit definition of legitimacy. However, he defines legitimacy elsewhere, writing that "something is legitimate if it is in accord with the norms, values, beliefs, practices, and procedures accepted by a group" (Zelditch 2001b:33). 
11. This is not an exhaustive list of legitimacy types. Table 2 only shows types identified by the authors of the reviews as "[X] legitimacy" (e.g., pragmatic legitimacy, moral legitimacy, cognitive legitimacy; see Suchman 1995).

12. I use the term audience to refer to the source of legitimacy judgments. I selected this term because it is used by half of the review articles, and its use refers to a variety of entities, ranging from individuals and small groups to entire organizations or populations. Across the remaining reviews, no common term presents an evident alternative. Adoption of this term is intended to reflect the most common practice, not to impose particular theoretical assumptions of individualism, motive, or passivity that might be associated with the term "audience" in other contexts.

13. Two nodes can have multiple relationships that are analytically distinct. For example, a married couple that also works together has at least two potentially distinct relationships: spouses and colleagues.

14. This does not mean expectations are created anew in every specific dyad. For example, a client's relationship with an accountant may be determined by broader social expectations linked to that profession. Expectations do not have to be specific to a particular interpersonal relationship.

15. Notably, the temporal relationship between conformity and legitimacy inverts when the focus is on conformity by the audience rather than the object. Research shows individuals (i.e., members of an audience) are more likely to conform to rules, status orders, or other social systems when those systems are legitimate (see Johnson et al. 2006; Zelditch 2001a). Thus, for example, a set of rules is legitimate if it conforms to "the norms, values, beliefs, practices, and procedures of a pre-given structure" (Zelditch 2001a:14), and legitimacy increases the 
probability individuals will behave in ways that conform to the rules (Beetham [1991] 2013; Johnson et al. 2006; Suddaby et al. 2017; Zelditch 2001a). Moreover, audience conformity can encourage continued conformity by the object. I want to thank an anonymous reviewer for raising this important point.

16. While field-theoretic analyses do not typically zoom in to the level of dyads, the underlying architecture of an institutional field is composed of interactions among members of the field (DiMaggio and Powell 1983:148). Dyads are thus implied, as they are the basic building blocks of the social relationships that constitute the field (White 2008; see also Fligstein and McAdam 2012).

\section{References}

Abbott, Andrew. 1988a. "Transcending General Linear Reality.” Sociological Theory 6(2):16986.

Abbott, Andrew. 1988b. The System of Professions: An Essay on the Division of Expert Labor. Chicago: University of Chicago Press.

Aldrich, Howard E. and C. Marlene Fiol. 1994. "Fools Rush In? The Institutional Context of Industry Creation.” The Academy of Management Review 19(4):654-670.

Alexander, Victoria D., and Anne E. Bowler. 2021. "Contestation in Aesthetic Fields: Legitimation and Legitimacy Struggles in Outsider Art." Poetics 84 (https://doi.org/10.1016/j.poetic.2020.101485).

Bansal, Pratima and Iain Clelland. 2004. "Talking Trash: Legitimacy, Impression Management, and Unsystematic Risk in the Context of the Natural Environment." Academy of Management Journal, 47(1):93-103. 
Baum, Joel A. C., and Walter W. Powell. 1995. "Cultivating an Institutional Ecology of Organizations: Comment on Hannan, Carroll, Dundon, and Torres." American Sociological Review 60(4):529-38.

Beck, Colin J. 2014. "Reflections on the Revolutionary Wave in 2011." Theory and Society 43(2):197-223.

Beck, Colin J. 2017. "Revolutions: Robust Findings, Persistent Problems, and Promising Frontiers.” Pp. 168-83 in States and Peoples in Conflict, edited by M. Stohl, M. I. Lichbach, and P. N. Grabosky. New York: Routledge.

Beetham, David. [1991] 2013. The Legitimation of Power. London, UK: Macmillan International Higher Education.

Bourdieu, Pierre. 1994. "Rethinking the State: Genesis and Structure of the Bureaucratic Field." Sociological Theory 12(1):1-18.

Bradford, Ben, Jonathan Jackson, and Mike Hough. 2013. Police Legitimacy in Action: Lessons for Theory and Practice. SSRN Scholarly Paper, ID 2236691. Rochester, NY: Social Science Research Network.

Breiger, Ronald L. 2000. “A Tool Kit for Practice Theory.” Poetics 27(2-3):91-115.

Castilla, Emilio J., and Stephen Benard. 2010. "The Paradox of Meritocracy in Organizations." Administrative Science Quarterly 55(4):543-676.

Centola, Damon. 2015. “The Social Origins of Networks and Diffusion.” American Journal of Sociology 120(5):1295-338.

Centola, Damon, Robb Willer, and Michael Macy. 2005. “The Emperor’s Dilemma: A Computational Model of Self-Enforcing Norms.” American Journal of Sociology 110(4):1009-40. 
Chenoweth, Erica, and Maria J. Stephan. 2011. Why Civil Resistance Works: The Strategic Logic of Nonviolent Conflict. New York: Columbia University Press.

Coleman, James S. 1994. Foundations of Social Theory. Cambridge, MA: Harvard University Press.

Correll, Shelley J. 2017. "SWS 2016 Feminist Lecture: Reducing Gender Biases in Modern Workplaces: A Small Wins Approach to Organizational Change.” Gender \& Society 31(6):725-50.

Correll, Shelley J., Cecilia L. Ridgeway, Ezra W. Zuckerman, Sharon Jank, Sara Jordan-Bloch, and Sandra Nakagawa. 2017. 'It's the Conventional Thought That Counts: How ThirdOrder Inference Produces Status Advantage.” American Sociological Review 82(2):297327.

DiMaggio, Paul J., and Walter W. Powell. 1983. “The Iron Cage Revisited.” American Sociological Review 48(2):147-60.

Dowling, John and Jeffrey Pfeffer. 1975. “Organizational Legitimacy: Social Values and Organizational Behavior.” Pacific Sociological Review. 18(1):122-136.

Drori, Israel and Benson Honig. 2013. "A Process Model of Internal and External Legitimacy." Organization Studies 34(3):345-376.

Duyvesteyn, Isabelle. 2017. "Rebels and Legitimacy: An Introduction.” Small Wars \& Insurgencies 28(4-5):669-85.

Emirbayer, Mustafa. 1997. "Manifesto for a Relational Sociology.” American Journal of Sociology 103(2):281-317.

Erikson, Emily. 2013. "Formalist and Relationalist Theory in Social Network Analysis." Sociological Theory 31(3):219-42. 
Ermakoff, Ivan. 2015. “The Structure of Contingency.” American Journal of Sociology 121(1):64-125.

Ermakoff, Ivan. 2017. "Shadow Plays: Theory’s Perennial Challenges.” Sociological Theory 35(2):128-37.

Ermakoff, Ivan, and Marko Grdesic. 2019. "Institutions and Demotions: Collective Leadership in Authoritarian Regimes." Theory and Society 48(4):559-87.

Fligstein, Neil, and Doug McAdam. 2012. A Theory of Fields. Oxford, UK: Oxford University Press.

Fuhse, Jan A. 2009. "The Meaning Structure of Social Networks." Sociological Theory 27(1):51-73.

Gilley, Bruce. 2009. The Right to Rule: How States Win and Lose Legitimacy. New York: Columbia University Press.

Goldstone, Jack A. 1991. Revolution and Rebellion in the Early Modern World. Berkeley: University of California Press.

Goldstone, Jack A. 2001. "Toward a Fourth Generation of Revolutionary Theory.” Annual Review of Political Science 4(1):139-87.

Goodwin, Jeff. 2001. No Other Way Out: States and Revolutionary Movements, 1945-1991. Cambridge, UK: Cambridge University Press.

Greenwald, Anthony G. 2012. "There Is Nothing So Theoretical as a Good Method." Perspectives on Psychological Science 7(2):99-108.

Haack, Patrick, Oliver Schilke, and Lynne Zucker. 2021. "Legitimacy Revisited: Disentangling Propriety, Validity, and Consensus.” Journal of Management Studies 58(3):749-81. 
Haack, Patrick, and Jost Sieweke. 2020. “Advancing the Measurement of Organizational Legitimacy, Reputation, and Status: First-Order Judgments vs. Second-Order Judgments - Commentary on 'Organizational Legitimacy, Reputation and Status: Insights from Micro-Level Management."” Academy of Management Discoveries $6(1): 153-58$.

Hafner-Burton, Emilie M., and Kiyoteru Tsutsui. 2005. "Human Rights in a Globalizing World: The Paradox of Empty Promises.” American Journal of Sociology 110(5):1373-411.

Hahl, Oliver, Minjae Kim, and Ezra W. Zuckerman Sivan. 2018. "The Authentic Appeal of the Lying Demagogue: Proclaiming the Deeper Truth about Political Illegitimacy.” American Sociological Review 83(1):1-33.

Hannan, Michael T., Glenn R. Carroll, Elizabeth A. Dundon, and John Charles Torres. 1995. "Organizational Evolution in a Multinational Context: Entries of Automobile Manufacturers in Belgium, Britain, France, Germany, and Italy.” American Sociological Review 60(4):509-28.

Hollis, Duncan B. 2002. "Private Actors in Public International Law: Amicus Curiae and the Case for the Retention of State Sovereignty." Boston College International and Comparative Law Review 25(2):235-55.

Jackson, Jonathan. 2018. "Norms, Normativity, and the Legitimacy of Justice Institutions: International Perspectives." Annual Review of Law and Social Science 14(1):145-65.

Jackson, Jonathan, Aziz Z. Huq, Ben Bradford, and Tom R. Tyler. 2013. “Monopolizing Force? Police Legitimacy and Public Attitudes toward the Acceptability of Violence.” Psychology, Public Policy, and Law 19(4):479-97. 
Johnson, Cathryn, Timothy J. Dowd, and Cecilia L. Ridgeway. 2006. "Legitimacy as a Social Process." Annual Review of Sociology 32(1):53-78.

Jost, John T., and Brenda Major. 2001. The Psychology of Legitimacy: Emerging Perspectives on Ideology, Justice, and Intergroup Relations. Cambridge, UK: Cambridge University Press.

Kostova, Tatiana and Srilata Zaheer. 1999. "Organizational Legitimacy Under Conditions of Complexity: The Case of the Multinational Enterprise." Academy of Management Review 24(1):64-81.

Kurzman, Charles. 2004. The Unthinkable Revolution in Iran. Cambridge, MA: Harvard University Press.

LaFree, Gary, and Nancy A. Morris. 2012. "Does Legitimacy Matter? Attitudes toward AntiAmerican Violence in Egypt, Morocco, and Indonesia." Crime \& Delinquency 58(5):689-719.

Lawson, George. 2016. "Within and Beyond the 'Fourth Generation' of Revolutionary Theory." Sociological Theory 34(2):106-27.

Levi Margaret and Audrey Sacks A. 2009. "Legitimating Beliefs: Sources and Indicators." Regulation \& Governance 3(4):311-33.

Luft, Aliza. 2020. "Religion in Vichy France: How Meso-Level Actors Contribute to Authoritarian Legitimation.” European Journal of Sociology 61(1):67-101.

Marquez, Xavier. 2016. “The Irrelevance of Legitimacy.” Political Studies 64(1_suppl):19-34.

Mazerolle, Lorraine, Emma Antrobus, Sarah Bennett, and Tom R. Tyler. 2013. "Shaping Citizen Perceptions of Police Legitimacy: A Randomized Field Trial of Procedural Justice." Criminology 51(1):33-63. 
Mazerolle, Lorraine, Sarah Bennett, Jacqueline Davis, Elise Sargeant, and Matthew Manning. 2013. "Legitimacy in Policing: A Systematic Review." Campbell Systematic Reviews 9(1)(https://doi.org/10.4073/csr.2013.1).

Meyer, John W. and Brian Rowan. 1991. "Institutionalized organizations: Formal structure as myth and ceremony." Pp. 41-62 in The New Institutionalism in Organizational Analysis, edited by W.W. Powell and P.J. DiMaggio. Chicago: University of Chicago Press.

Molm, Linda D. 2006. “The Social Exchange Framework.” Pp. 24-45 in Contemporary Social Psychological Theories, edited by P. J. Burke. Stanford, CA: Stanford University Press. Nepstad, Sharon Erickson. 2011. Nonviolent Revolutions: Civil Resistance in the Late 20th Century. Oxford, UK: Oxford University Press.

O’Kane, Rosemary H. T. 1993. “Against Legitimacy.” Political Studies 41(3):471-87.

Pachucki, Mark A., and Ronald L. Breiger. 2010. “Cultural Holes: Beyond Relationality in Social Networks and Culture." Annual Review of Sociology 36:205-24.

Pakulski, Jan. 1986. “Legitimacy and Mass Compliance: Reflections on Max Weber and SovietType Societies.” British Journal of Political Science 16(1):35-56.

Ray, Victor. 2019. “A Theory of Racialized Organizations.” American Sociological Review 84(1):26-53.

Ridgeway, C. L. (2001). The emergence of status beliefs: From structural inequality to legitimizing ideology. Pp. 257-277 in The psychology of legitimacy: Emerging perspectives on ideology, justice, and intergroup relations, edited by J. T. Jost and B. Major. Cambridge, UK: Cambridge University Press.

Ridgeway, Cecilia L. 2011. Framed by Gender: How Gender Inequality Persists in the Modern World. Oxford, UK: Oxford University Press. 
Ridgeway, Cecilia L., and Shelley J. Correll. 2006. "Consensus and the Creation of Status Beliefs." Social Forces 85(1):431-53.

Risse, Thomas, and Eric Stollenwerk. 2018. "Legitimacy in Areas of Limited Statehood." Annual Review of Political Science 21(1):403-18.

Ruef, Martin and W. Richard Scott. 1998. "A Multidimensional Model of Organizational Legitimacy: Hospital Survival in Changing Institutional Environments.” Administrative Science Quarterly 43(4):877-904.

Schoon, Eric W. 2014. "The Asymmetry of Legitimacy: Analyzing the Legitimation of Violence in 30 Cases of Insurgent Revolution.” Social Forces 93(2):779-801.

Schoon, Eric W. 2015. "The Paradox of Legitimacy: Resilience, Successes, and the Multiple Identities of the Kurdistan Workers' Party in Turkey.” Social Problems 62(2):266-85.

Schoon, Eric W. 2016. "Rethinking Legitimacy and Illegitimacy in Violent Political Conflict." Sociology Compass 10(2):143-152.

Schoon, Eric W., Alexandra Pocek Joosse, and H. Brinton Milward. 2020. "Networks, Power, and the Effects of Legitimacy in Contentious Politics.” Sociological Perspectives 63(4):670-90.

Schoon, Eric W., and A. Joseph West. 2018. "From Prophecy to Practice: Mutual Selection Cycles in the Routinization of Charismatic Authority." Journal for the Scientific Study of Religion 56(4):781-97.

Scott, W. Richard. 1977. "Effectiveness of Organizational Effectiveness Studies." Pp. 63-96 in New Perspectives on Organizational Effectiveness, edited by P.S. Goodman and J.M. Pennings. San Francisco: Jossey-Bass. 
Scott, W. Richard. 1995. Institutions and Organizations: Ideas, Interests, and Identities. Newbury Park, CA: Sage.

Selznick, Phillip. 1949. TVA and the Grass Roots: A Study in the Sociology of Formal Organizations. Berkeley: University of California Press.

Sharman, J. C. 2003. “Culture, Strategy, and State-Centered Explanations of Revolution, 1789 and 1989." Social Science History 27(1):1-24.

Simmel, Georg. 1964. The Sociology of Georg Simmel, edited by K. H. Wolff. New York: Free Press.

Singh, Sourabh. 2016. "What Is Relational Structure? Introducing History to the Debates on the Relation between Fields and Social Networks.” Sociological Theory 34(2):128-50.

Skocpol, Theda. 1979. States and Social Revolutions: A Comparative Analysis of France, Russia and China. Cambridge, UK: Cambridge University Press.

Stryker, Robin. 1994. "Rules, Resources, and Legitimacy Processes: Some Implications for Social Conflict, Order, and Change." American Journal of Sociology 99(4):847-910.

Suchman, Mark C. 1995. "Managing Legitimacy: Strategic and Institutional Approaches.” Academy of Management Review 20(3):571-610.

Suddaby, Roy, Alex Bitektine, and Patrick Haack. 2017. "Legitimacy.” Academy of Management Annals 11(1):451-78.

Tankebe, Justice. 2013. "Viewing Things Differently: The Dimensions of Public Perceptions of Police Legitimacy.” Criminology 51(1):103-35.

Tost, Leigh Plunkett. 2011. “An Integrative Model of Legitimacy Judgments.” Academy of Management Review 36(4):686-710. 
Tyler, Tom R. 1997. “Citizen Discontent with Legal Procedures: A Social Science Perspective on Civil Procedure Reform.” American Journal of Comparative Law 45(4):871-904.

Tyler, Tom R. 2006. "Psychological Perspectives on Legitimacy and Legitimation.” Annual Review of Psychology 57(1):375-400.

Walker, Edward T., and John D. McCarthy. 2010. "Legitimacy, Strategy, and Resources in the Survival of Community-Based Organizations." Social Problems 57(3):315-40.

Walker, Henry A., and David Willer. 2014. "Legitimizing Collective Action and Countervailing Power." Social Forces 92(3):1217-39.

Wasserman, Stanley, and Katherine Faust. 1994. Social Network Analysis: Methods and Applications. Cambridge, UK: Cambridge University Press.

Weber, Max. [1921] 1978. Economy and Society: An Outline of Interpretive Sociology. Berkeley: University of California Press.

Weber, Max. 2004. The Vocation Lectures. Indianapolis, IN: Hackett Publishing.

White, Harrison C. 2008. Identity and Control: How Social Formations Emerge. Princeton, NJ: Princeton University Press.

Zelditch, Morris. 2001a. "Processes of Legitimation: Recent Developments and New Directions." Social Psychology Quarterly 64(1):4-17.

Zelditch, Morris. 2001b. "Theories of Legitimacy." Pp. 33-53 in The Psychology of Legitimacy: Emerging perspectives on ideology, justice, and intergroup relations, edited by J. Jost and B. Major. Cambridge, UK: Cambridge University Press.

Zelditch, Morris, and Henry A. Walker. 2003. "The Legitimacy of Regimes.” Pp. 217-39 in Power and Status, Vol. 20, Advances in Group Processes, edited by S. R. Thye and J. 
Skvoretz. Bingley, UK: Emerald Group Publishing Limited (https://doi.org/10.1016/S0882-6145(03)20008-4).

Zucker, Lynne G. 1986. "Production of trust: Institutional Sources of Economic Structure, 1840-1920.” Research in Organizational Behavior. 8: 53-111.

Zucker, Lynne G. 1991. "The role of institutionalization in cultural persistence." Pp. 83-107 in The New Institutionalism in Organizational Analysis, edited by W.W. Powell and P.J. DiMaggio. Chicago: University of Chicago Press.

Zuckerman, Ezra W. 1999. "The Categorical Imperative: Securities Analysts and the Illegitimacy Discount." American Journal of Sociology 104(5):1398-438. 
Table 1. Summary of Legitimacy Reviews

\begin{tabular}{llcc}
\hline & & & $N$ Legitimacy \\
Author (Date) & Outlet & Works Cited & 105 \\
Definitions \\
\hline Jackson (2018) & Annual Review of Law and Society & 116 & 3 \\
Johnson, Dowd, and Ridgeway (2006) & Annual Review of Sociology & 164 & 7 \\
Mazerolle, Bennett, et al. (2013) & Campbell Systematic Reviews & 115 & 2 \\
Risse and Stollenwerk (2018) & Annual Review of Political Science & 120 & 3 \\
Suchman (1995) & Academy of Management Review & 245 & 4 \\
Suddaby, Bitektine, and Haack (2017) & Academy of Management Annals & 169 & 2 \\
Tyler (2006) & Annual Review of Psychology & 76 & 6 \\
Zelditch (2001a) & Social Psychology Quarterly & 0 \\
\hline
\end{tabular}

Note: Partial results of Mazerolle, Bennett, and colleague's (2013) meta-analysis were published in journal article format in the Journal of Experimental Criminology, but the report published in Campbell Systematic Reviews - a publication by the Norway-based nonprofit Campbell Collaboration-provides a more detailed review of their work. I therefore include the more comprehensive review. 
Table 2. Types of Legitimacy

\begin{tabular}{|c|c|c|c|c|c|}
\hline \multirow[b]{2}{*}{ Legitimacy Type } & \multicolumn{3}{|c|}{ Basis of Distinction } & \multirow[b]{2}{*}{ Subtype of.. } & \multirow[b]{2}{*}{ Source } \\
\hline & $\begin{array}{c}\text { Source of } \\
\text { Legitimacy }\end{array}$ & $\begin{array}{c}\text { Object of } \\
\text { Legitimacy }\end{array}$ & $\begin{array}{l}\text { Evaluative } \\
\text { Framework }\end{array}$ & & \\
\hline Categorical legitimacy & & & $\bullet$ & Moral legitimacy & Zucker (1986) \\
\hline Cognitive legitimacy & & & • & & Suchman (1995) \\
\hline Consequential legitimacy & & & • & Moral legitimacy & Meyer and Rowan (1991) \\
\hline Corporate environmental legitimacy & & & $\bullet$ & & Bansa and Clelland (2004) \\
\hline Dispositional legitimacy & & & $\bullet$ & Pragmatic legitimacy & Suchman (1995) \\
\hline Empirical legitimacy & - & & & & Levi and Sacks (2009) \\
\hline Exchange legitimacy & & & - & Pragmatic legitimacy & Dowling and Pfeffer (1975) \\
\hline External legitimacy & - & & & & Drori and Honig (2013); Kostova and Zaheer (1999) \\
\hline Influence legitimacy & & & • & Pragmatic legitimacy & Selznick (1949) \\
\hline Internal legitimacy & & & $\bullet$ & & Drori and Honig (2013); Kostova and Zaheer (1999) \\
\hline Legal legitimacy & & & $\bullet$ & & Hollis (2002); Tyler (1997) \\
\hline Local legitimacy & $\bullet$ & & & & Risse and Stollenwerk (2018) \\
\hline Managerial legitimacy & & - & & & Ruef and Scott (1998) \\
\hline Moral legitimacy & & & - & & Suchman (1995) \\
\hline Normative legitimacy & & & $\bullet$ & & Levi and Sacks (2009); Scott (1995) \\
\hline Organizational legitimacy & & - & & & Kostova and Zaheer (1999) \\
\hline Personal legitimacy & & $\bullet$ & & & Zucker (1991) \\
\hline Police legitimacy & & • & & Empirical legitimacy & Jackson (2018) \\
\hline Popular legitimacy & - & & & Empirical legitimacy & Jackson (2018) \\
\hline Pragmatic legitimacy & & & • & & Suchman (1995) \\
\hline Procedural legitimacy & & & $\bullet$ & Moral legitimacy & Scott (1995) \\
\hline Regulative legitimacy & & & $\bullet$ & & $\operatorname{Scott}(1995)$ \\
\hline Sociopolitical legitimacy & & & - & & Aldrich and Fiol (1994) \\
\hline Structural legitimacy & & & - & Moral legitimacy & Scott (1977) \\
\hline Technical legitimacy & & & - & & Ruef and Scott (1998) \\
\hline
\end{tabular}

Note: Sources listed are those cited by a review in reference to a particular legitimacy type; in cases where a specific earlier reference was not provided, the review itself is listed. 


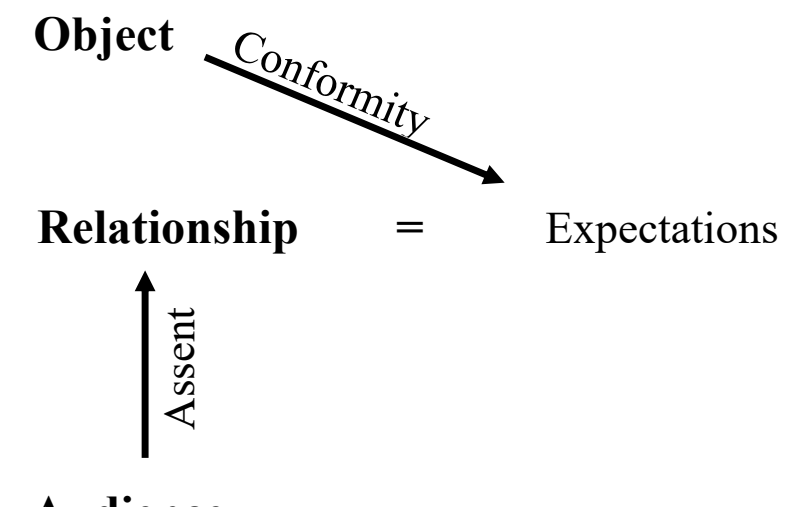

Figure 1. Relationship between Empirical Components and Necessary Conditions for Legitimacy Note: Empirical components 